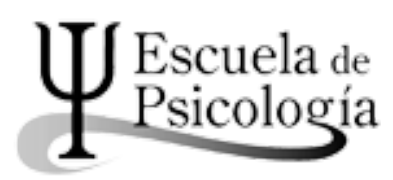

Wímblu, Rev. estudiantes Esc. de psicología, Univ. de Costa Rica. 12 (2): 93-100, 2017 / ISSN: 1659-2107

\title{
El lugar de lo ominoso \\ Una lectura a la apuesta estética de Gaspar Noé, hacia una propuesta de enseñanza en la Psicología
}

\author{
The place of the ominous \\ A reading to the esthetic bet of Gaspar Noé, towards a proposal of teaching in the Psychology
}

Francisco Acuña Saborio*

\begin{abstract}
Resumen: Un esfuerzo como el emprendimiento realizado en la jornada Psinema en la Universidad de Costa Rica da cuenta del amplio interés por parte de estudiantes y docentes de la Escuela de Psicología en discutir y reflexionar sobre las maneras más idóneas de utilizar el cine (documental, ficción, cortometrajes, largometrajes, video-ensayos) como herramienta que propicie algún saber. Este escrito propone una analogía entre la obra creativa del director Gaspar Noé y atributos fundamentales para lograr una pedagogía que tome en cuenta lo ominoso, en tanto elemento prevaleciente en la estética, argumentando que lo estético no es de ningún modo ajeno o superfluo a los procesos de enseñanza.

Palabras clave: Estética, Cine independiente, Lo ominoso, Gaspar Noé, Enseñanza.
\end{abstract}

Abstract: An effort as the undertaking that took place in the conference Psinema at the Universidad de Costa Rica it's an example of students and teachers' wide interest in the Escuela de Psicología to discuss and reflect about the most appropriate ways to use cinema (documental, fiction, short-films, full-length films, video-essays) as a tool to encourage a certain knowledge. This article proposes an analogy between the creative work of director Gaspar Noé and fundamental attributes to accomplish a pedagogy which considers the uncanny, as a prevailing element in esthetics, arguing that esthetics isn't at all unconnected, or superfluous to the process of teaching.

Key Words: Esthetic, independent cinema, The uncanny, Gaspar Noé, Teaching.

* Universidad de Costa Rica. Bachiller en Psicología, presentador y programador de Los Viernes Cinefilos en La Alianza Francesa de Costa Rica. Correo electrónico: fran.acuna.09@gmail.com

Recepción: 28/3/2017 Aceptación: 22/8/2017 
El arte valiente, que puede trascender el dualismo arbitrario entre lo que se puede $o$ no se puede decir, entre lo sublime y lo vulgar, entre lo erudito y lo popular ha sido históricamente acuñado desde disciplinas como la Filosofía, el Psicoanálisis, la Teoría Queer y los Gay and Lesbian Studies. La voluptuosa filosofía literaria de Sade, el lirismo erótico de Sacher-Masoch, los héroes de valores invertidos de Jean Genet, lo vulgar como trascendente en la ficción de Bataille, han encontrado un nicho en lo académico que revindica tales letras en lugar de despreciarlas como corrosivas. Similar argumento se podría proponer de la obra de variopintos realizadores cinematográficos como Dario Argento, Buñuel, Pasolini, Haneke y el director por el cual se escriben estas líneas: Gaspar Noé.

La obra cinematográfica de Gaspar Noé es comúnmente catalogada por terceros como parte de La nueva ola de cine extremo francés. Presenta sin rechistar un sujeto bastante alejado del homo noumenon kantiano. La naturaleza racional y moral de sus personajes está puesta en duda, abriendo así camino para retratar seres que no siempre tienen control sobre sí, que pueden (como en la vida misma) estar tomados por un imperativo de goce, que desean con intensidad y ese deseo no siempre apunta hacia el bienestar o a la salud. Conceptos teleológicos como estilos de vida saludable, salud mental y autocuidado son puestos en tela de juicio.

La lectura de Noé sobre el sujeto me parece valiosa en tanto acepta dentro de ella lo ominoso, entendido por Freud como "aquella variedad de lo terrorífico que se remonta a lo consabido de antiguo, a lo familiar desde hace largo tiempo" (Freud, 1992, p. 220). Lo ominoso suele estar acompañado por la angustia, por la incomodidad de no estar muy seguros de si ese objeto que causa tal conmoción en nosotros pertenece a algo de nosotros mismos o está desterrado al ser de otra naturaleza, es, permitiéndome el anglicismo, el uncanny valley de las figuras de cera y las manifestaciones de locura que podemos atestiguar en otro. Nos cuestiona en tanto que por más que rechacemos tal idea, la división entre el loco y el sano es un artificio arbitrario, cualquiera puede devenir loco. ¿Será por ello que la locura se segrega socialmente? Porque nos podemos ver reflejados en la mirada del que consideramos delirante.

Tal gesto de segregación ha devenido estructural en la historia, así lo atestigua la teoría foucaultiana, la Teoría Crítica y la Antipsiquiatría:

El comportamiento de aquellas personas cuya conducta difiere de la de sus semejantes, sea por no alcanzar la norma habitual del grupo, sea por superarla, constituye un misterio o una amenaza similares; los conceptos de posesión diabólica y locura proporcionan una teoría rudimentaria para explicar tales sucesos y métodos apropiados para hacerles frente (Szasz, 1991, p. 24)

Ese ominoso misterio es de lo que se encarga Gaspar Noé en sus largometrajes; en Seul contre tous (1998) retrata a un padre que recién obtiene la libertad después de un tiempo en la cárcel y su lucha interna respecto a los sentimientos incestuosos que tiene por su hija, todo esto mientras el espectador escucha sin descanso sus interminables rumiaciones; Irreversible (2002) narra la violenta venganza del protagonista, que acontece al no poder dominar su angustia al enterarse que su novia fue violentada y degradada, realizando la película a su vez una interesante reflexión sobre el azar y la vacuidad de lo que consideramos certero, proponiendo un ejercicio de montaje inverso bastante atípico; en Enter the void (2009) presenciamos el viaje metafísico y místico al estar a las puertas de la muerte de un dealer y consumidor de drogas, considerado como basura social; y en su más reciente filme, Love (2015), Noé no se inhibe al abordar el tabú de la sexualidad poligámica de una forma gráfica y natural, ganándose con ello varios intentos de censura en Francia, utilizando, los medios censuradores, despectivamente el argumento de ser un trabajo pornográfico.

La completa lista de largometrajes de Noé es difícil de digerir, pero es también asombrosamente humana, siendo profundamente desconcertante por su empeño constante en evitar el simplismo moral del binario correcto/incorrecto. Nos turba, al mismo tiempo que propone la empatía y la identificación con sus sufrientes personajes; no los presenta como un caso ajeno de la experiencia humana, sino como un caso extremo de lo que puede existir en cada uno de nosotros. La segregación social hacia los seres que no queremos admitir como parte de lo humano, los simbolismos que se bifurcan y lo ominoso el común denominador de su filmografía.

\section{Pedagogía subversiva}

...Pero ¿A qué viene esto en relación a una propuesta pedagógica en la Psicología?

Como mencioné anteriormente, mi argumento deviene de la consideración de lo estético como un aspecto esencial en un proceso de aprendizaje integral. En este caso, comparto lo planteado por Fernández (2010) al afirmar que los productos artísticos y estéticos "problematizan sus propias aspiraciones formalizadoras y estructurantes, plantean relaciones complejas entre lo que quisiéramos llamar la forma y el fondo, o continente y contenido" (p. 53). Concuerdo también con su posición al argumentar que la estética no es solamente un interés subjetivo pequeño burgués, respaldando perderle el miedo a que la Psicología se vuelva algo "muy artístico, literario, filosófico," (p. 55) cuando no teníamos problemas en que sea algo "algo muy científico-natural, muy técnico, muy pragmático, muy operativo, muy médico, muy psiquiátrico, muy psicofarmacológico" (p. 55).

Desde tal precepto, la Psicología y su enseñanza no debe aislarse de manifestaciones artísticas que pueden tener también mucho que decir no solamente sobre el proceso de creación de la obra, sino también del discurso 
mismo de la obra que revela posicionamientos novedosos y fascinantes sobre la psique humana, sobre la llamada locura, sobre cualquier tema concerniente a la Psicología, que incluso pueden llegar a socavar ideologías y firmezas a lo interno de la disciplina.

El tratamiento de lo controversial en la apuesta estética de Gaspar Noé, así como sus recursos narrativos y el contenido de su trabajo me resultan evocadores al plantearme un posible paralelismo con respecto a una propuesta pedagógica en la Psicología. No es controversia por solamente el valor de la controversia, no es provocación estéril, sino una utilización de tal recurso que de todos modos es ineludible a la hora de plantearse preguntas sobre el pensar, sentir y actuar del sujeto. Irremediablemente los temas tabú deben ser abordados, y muy deseablemente sin un imperativo moralista que acalle el concubinato entre la prohibición y el placer, la ley y el deseo. Desperdigar una teoría porque no se ajusta a la visión más optimista del ser humano es un acto de censura epistémica. La obra de arte, así como la obtención de un cierto saber es un acontecimiento traumático, y sería reaccionario acallarlo a favor de alguna corrección política. En esta misma línea, me parece pertinente lo postulado por Susan Sontag (2011) al referirse a aquello que hace que una obra de arte tenga la posibilidad de perdurar:

Este sentido descarnado produce a menudo una suerte de ansiedad, parecida a la que experimentamos cuando los objetos familiares no están en su lugar o no desempeñan su papel habitual. [...] experimentamos algo parecido a esa mezcla de ansiedad, distanciamiento, escozor y alivio [...] (p. 30)

Ese shock descrito por Sontag, correlato de algo reprimido que retorna, estaría directamente emparentado con lo ominoso, porque eso que retorna porta también algún otro afecto. Para Freud, lo ominoso adquiere su estatuto al ser algo familiar, antiguo en la vida anímica, sólo enajenado de ella por el proceso de la represión. Lo que estaba destinado a permanecer oculto sale a la luz y en primera instancia este erizamiento de difícil nominación es inevitable. En el proceso de aprendizaje se manifiesta cuando sentimos incertidumbre de nuestro conocimiento científico, cuando algo no se ajusta fácilmente a nuestros esquemas vitales, cuando lo que queremos eludir nos ve de frente.

Seul contre tous (1998) nos confronta con lo ominoso al presentarnos de manera descarnada la intensidad de nuestras reacciones afectivas originarias; Irreversible (2002) al plantearnos la posibilidad del otro convertido en enemigo dañándonos con el beneplácito de la imprevista fuerza del azar; en Enter the void (2009) se abre un lugar a la representación de nuestra propia mortalidad a la que tan poco espacio concede nuestro inconsciente, al tiempo que explora recuerdos infantiles reprimidos por el protagonista; y Love (2015) desmitifica la sexualidad sin ocultar a su vez su ápice trágico.
En todos sus filmes, en el espectador se gesta alguna condición de la represión ligeramentefranqueada, necesaria para que lo primitivo pueda retornar como algo ominoso.

Pero la búsqueda por lo ominoso no debe ser el telos del esfuerzo creativo o de enseñanza, como dije anteriormente, la provocación no basta, sino aquel proceso que se lleva a cabo una vez que la incomodidad ha acaecido. El filósofo Slavoj Zizek (2010) elabora esto de la siguiente manera:

Una obra de arte moderna, es "incomprensible" por definición, funciona como un shock, como la irrupción de un trauma que socava la complacencia de nuestra rutina cotidiana y se resiste a la integración en el universo simbólico de la ideología prevaleciente; despues de este primer encuentro, la interpretacion entra en escena y nos permite integrar ese shock: digamos que nos informa que ese trauma registra ese sentido, la interpretación es el momento decisivo del acto de la recepción. (p. 7)

Así, lo ominoso puede resemantizar el choque, intervenirnos subjetivamente, ser la angustiosa puerta de entrada a un cambio perceptivo y libidinal que involucra al cuerpo y al deseo. El aprendizaje y la contemplación estética pasan de esta manera por un lugar que trasciende el logos, son experiencias que comprometen pulsionalmente, de esta forma una enseñanza en Psicología no puede no ser erotológica.

Evitar a toda costa lo ominoso en la enseñanza de la Psicología es una forzosa condescendencia hacia la ontología del sujeto, que más que evidenciar una generosidad existencial, acusa un reproche moral que desoye ciertos aspectos de la vida psíquica y social, negándole derecho de representación a lo ya de todas formas abyecto.

\section{Pedagogía y emancipación}

"Yo dejé el final abierto, no quería que fuera obvio que era un sueño. Muchos creen que al final el personaje se reencarna...y no olviden que hago películas porque nunca fui al psicoanalista..." (Gaspar Noé, 2010)

Tomando en cuenta las características anteriormente formuladas sobre el cine que realiza Gaspar Noé, podemos percibir su constante renuencia a aportar un significado unívoco en cada obra, su mensaje juega con la ambigüedad, es en un tiempo sórdido y romántico, nihilista y esperanzador. Ahí está la clave de su naturaleza emancipadora. Para aportar tal argumento me baso en la teoría semiótica de Julia Kristeva (1998), dentro de la cual se plantea que desde lo cultural es posible subvertir los propios límites del registro simbólico por medio de Lo semiótico y Lo poético. 
Partiendo de que cualquier configuración y producción social dentro de la misma posee su propio lenguaje, Kristeva (1998) conjetura que tal lenguaje estaría dominado por un rígido sistema que lo limita con un imperativo de producción muy específico, aquel que no deja espacio al no todo, que se rige por binarios excluyentes, que evita el doble sentido. De esta forma los alcances del significante se estrechan culturalmente para evitar la angustia de una producción semántica que oriente a más de un significado.

Este devenir social tiene un marcado paralelismo con el desarrollo del enfant, que antes del contacto cultural tendría una naturaleza primigenia polimorfa, esto atañería la diversidad de las fuentes y de objetos pulsionales, y a un registro simbólico aun sin encausarse. Posteriormente, este perverso polimorfo, por medio de la separación materna y la irrupción de la cultura, amoldaría su libido, su habla, lo simbólico y la configuración erógena del cuerpo y al placer en base a demandas sociales que, conjeturo tienen como justificación latente la evitación de la indeterminación que puede hacer surgir lo ominoso.

Tomando lo anterior en cuenta, Kristeva (1998), plantea que mediante lo poético es posible una transformación crítica de lo simbólico que permita y dé espacio a nuevas formas de expresión, de aprendizaje y de comunicación, que lleguen justamente ahí donde la configuración estructural de lo simbólico en la sociedad evita llegar y que solo las experimentamos en los sueños, los actos fallidos, la imaginería inconsciente o los síntomas. La propuesta es trastocar lo simbólico por medio de las posibilidades que la cultura permite. En este caso, hablar desde lo poético sería una forma de hablar desde aquello anterior a cierto adoctrinamiento cultural recurriendo al lenguaje polimorfo, sin necesariamente caer fuera de los límites culturales, designados tan frecuentemente como el lugar de la locura. Lo poético, al problematizar la producción de sentido, al poner en duda lo unívoco y tautológico de lo simbólico, estaría a su vez produciendo el espacio en donde el aprendizaje es posible. De esa forma es como Kristeva proclama la posibilidad de crear nuevos sentidos remitiéndose desde la cultura a la impronta precultural. Mediante lo poético el significado pasa, de ser uno, a ser una serie de posibilidades infinitas.

Los significados aluden la obra de Gaspar Noé, en ella no persiste alguna interpretación unívoca de lo visto en pantalla, el celuloide se vuelve así el topos de lo ominoso. Esto lo logra evitando a toda costa la respuesta fácil a las cuestiones planteadas, evadiendo la dulce satisfacción de una obra que se comprende a sí misma, posibilitando el cuestionamiento de la unión impuesta entre significado y significante apuntándose entre sí, escapando del artificio de la respuesta certera, respetando así la integridad del espectador en tanto intérprete de la obra. En pocas palabras: desbarata el signo.
Jared Russell (2012) elabora al respecto:

Noé intenta mostrar lo que precisamente no puede ser mostrado, con el fin de mostrar lo que el esfuerzo de mostrar, representa - revelando significado - elude constantemente con el fin de comenzar a funcionar (...) Noé representa lo Real como algo que escapa, así como determina la clara oposición de lo Real y lo no-Real por medio de una intensa confrontación con la irreductibilidad de la pérdida. (párr. 5)

Al optar por una propuesta de pedagogía en la Psicología, tomando como analogía la manera en la que Noé utiliza lo semiótico, es menester tener en cuenta la dificultad de trascender las limitaciones del lenguaje mismo utilizando el signo impuesto, socialmente aceptado, avalado por las normas reguladoras de la semántica, tan apartadas del destello de poesía fértil que emana la irregularidad e incluso la inconveniencia del significante sorpresivo, que debilita las bases de la razón. Mostrando con ello que cualquier conocimiento no escapa de estar atado a un discurso de poder epistémico, moderador de lo que se debe y se puede decir, de las normas y usos que enajenan el decir orientándolo a lugares comunes, cuyo corolario es la más llana repetición.

\section{Concretando}

La aproximación propuesta entre Gaspar Noé y la Psicología y su enseñanza se da en dos modalidades: en tanto análisis del contenido del material en sí y en tanto analogía. De esta forma espero que con estas palabras el lector no familiarizado con la obra de Gaspar Noé pueda adentrarse en ella.

El escrito también realiza un llamado a no desperdiciar, en la academia y muy especialmente en los modelos de enseñanza en Psicología, un material por no contener una visión que en superficie parezca poco optimista hacia el ser humano (que en este caso en particular es la filmografía y los temas tratados por el director, pero que puede ser cualquier elemento que trascienda la corrección política y el entusiasmo ilusorio). Porque estas temáticas y una forma de tratamiento que no se decante por la respuesta impuesta y dogmática puede, mediante la provocación ominosa, fomentar un segundo momento en el cual, haciendo intervenir el afecto se revindique lo abyecto. Esto genera el espacio para un aprendizaje que intenta liberarse de las estratagemas reaccionarias del lenguaje impuesto, tan reiteradamente propuesto como única forma de relación con lo estético, con el otro, con el Otro, con el placer, con el deseo y con el saber. 


\section{Referencias consultada}

Fernández, M. (2010). Algunas consecuencias epistemológicas de pensar la estética en los principios de la formación en psicología. Revista Wimb lu, $6(1), 51-59$.

Freud, S. (1992). Lo ominoso. En: Obras Completas. Vol XVII. Buenos Aires, Argentina: Amorrortu Editores.

Gaspar, N. (director). (1998). Love [Cinta cinematográfica]. Francia: RT Features / Rectangle Productions / Wild Bunch

Gaspar, N. (director). (1998). Seul contre tous [Cinta cinematográfica]. Francia: Les Cinémas de la Zone / Canal + / Love Streams Productions.

Gaspar, N. (director). (2002). Irreversible [Cinta cinematográfica]. Francia: Nord-Ouest Productions / Eskwad / 120 Films / Les Cinemas de la zone / Studiocanal.

Gaspar, N. (director). (2009). Enter the void [Cinta cinematográfica]. Francia, Alemania, Italia: Fidélité Films / Wild Bunch / Les Films de la Zone / BUF / Essential Filmproduktion GmbH / BIM Distribuzione / Paranoid Films.

Kristeva, J. (1998). Sentido y sinsentido de la revuelta: literatura y psicoanálisis. Buenos Aires: Eudeba.

Noé, G. (entrevistado), Reale, C. (Entrevistadora). (2010). Gaspar Noé: "Hago películas porque nunca fui al psicoanalista". Recuperado de http://www. revistaenie.clarin.com/escenarios/cine/Gaspar-Noe-Hago-peliculaspsicoanalista-enterthevoid-cine_0_383361899.html.

Russell, J. (2010). The navel of the dream: Gaspar Noé's Enter the Void. Recuperado de: http://www.lacan.com/symptom15/?p=65

Sontag, S. (2011). Una estética del silencio. En: Estilos radicales. España: Debolsillo.

Szasz, T. (1991). Ideología y enfermedad mental. Buenos Aires, Argentina: Amorrortu Editores.

Zizek, S. (2010) Todo lo que usted siempre quiso saber sobre Lacan y nunca se atrevió a preguntarle a Hitchcock. Buenos Aires, Argentina: Manantial.

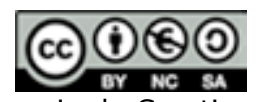

Esta obra está bajo una licencia de Creative Commons Reconocimiento

- NoComercial - CompartirIgual (by-nc-sa) 